(C) American Chemical Society, J. Phys. Chem. B, ms \# jp0368233 Supporting Info Page S1

\title{
Mesoporous Carbons Synthesized by Imprinting Ordered and Disordered Porous Structures of Silica Particles in Mesophase Pitch
}

Zuojiang Li, and Mietek Jaroniec

Department of Chemistry, Kent State University, Kent, Ohio 44242

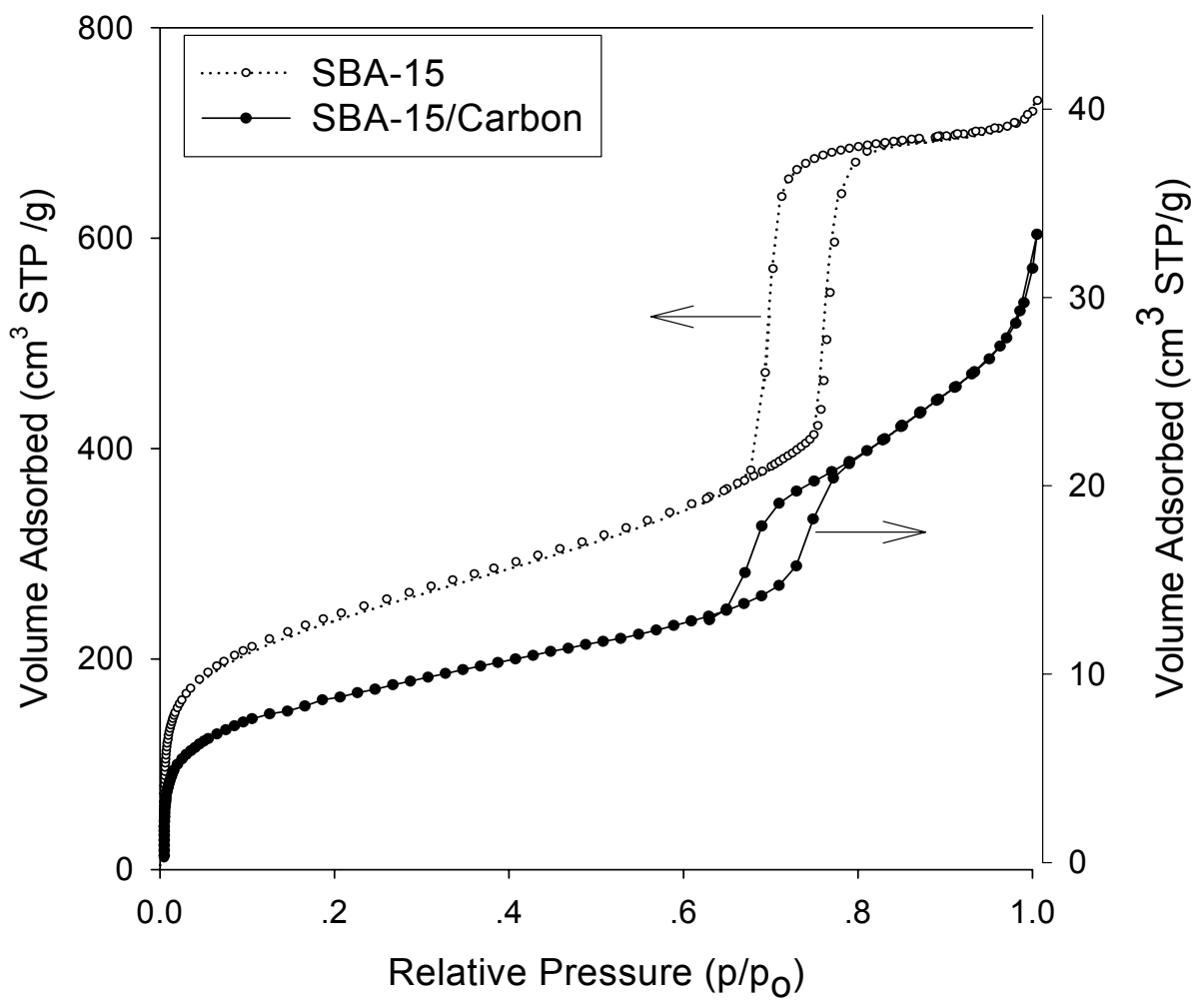

Figure 1S. Nitrogen adsorption isotherms for SBA-15 and SBA-15/carbon samples at $-196{ }^{\circ} \mathrm{C}$. 
(C) American Chemical Society, J. Phys. Chem. B, ms \# jp0368233 Supporting Info Page S2

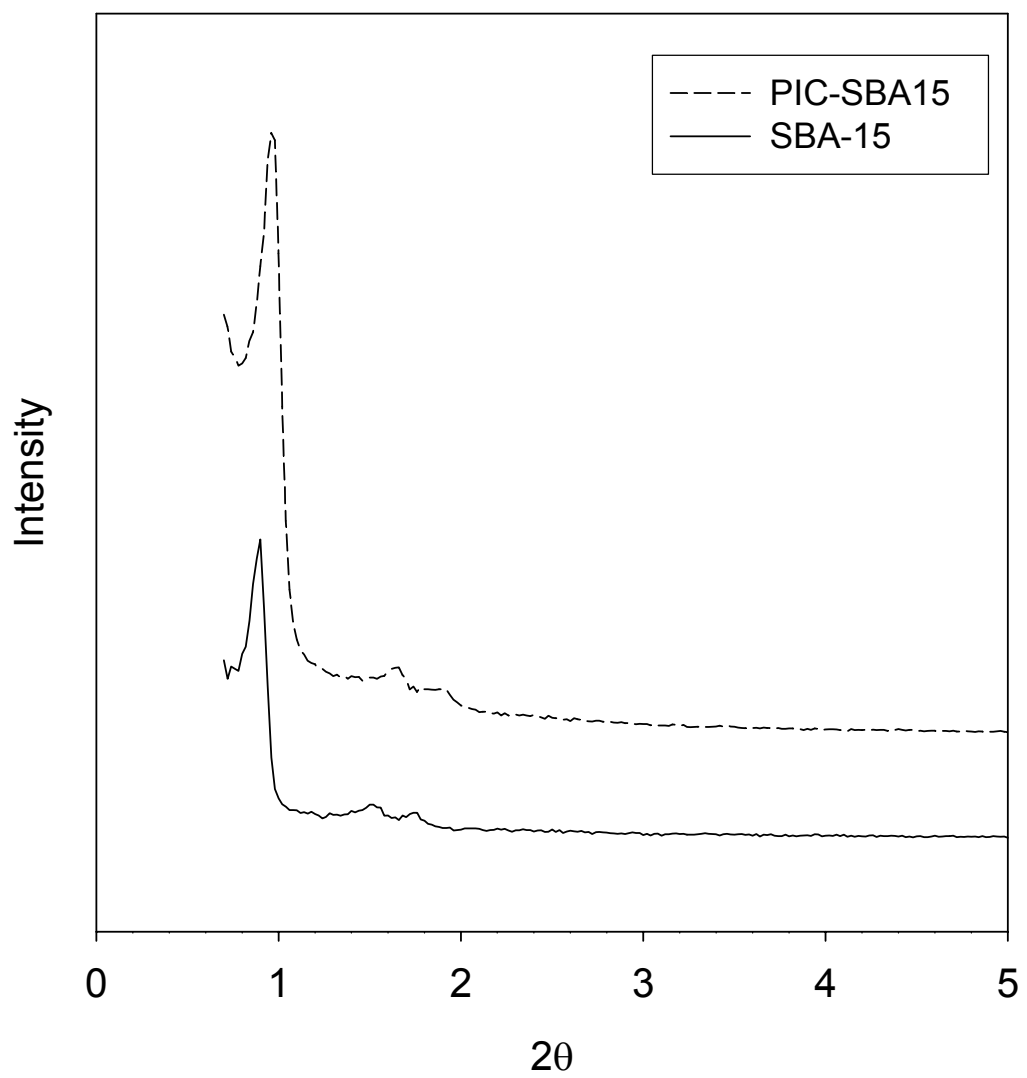

Figure 2S. X-ray diffraction patterns for the SBA-15 silica and the corresponding carbon, PICSBA15. 
(C) American Chemical Society, J. Phys. Chem. B, ms \# jp0368233 Supporting Info Page S3

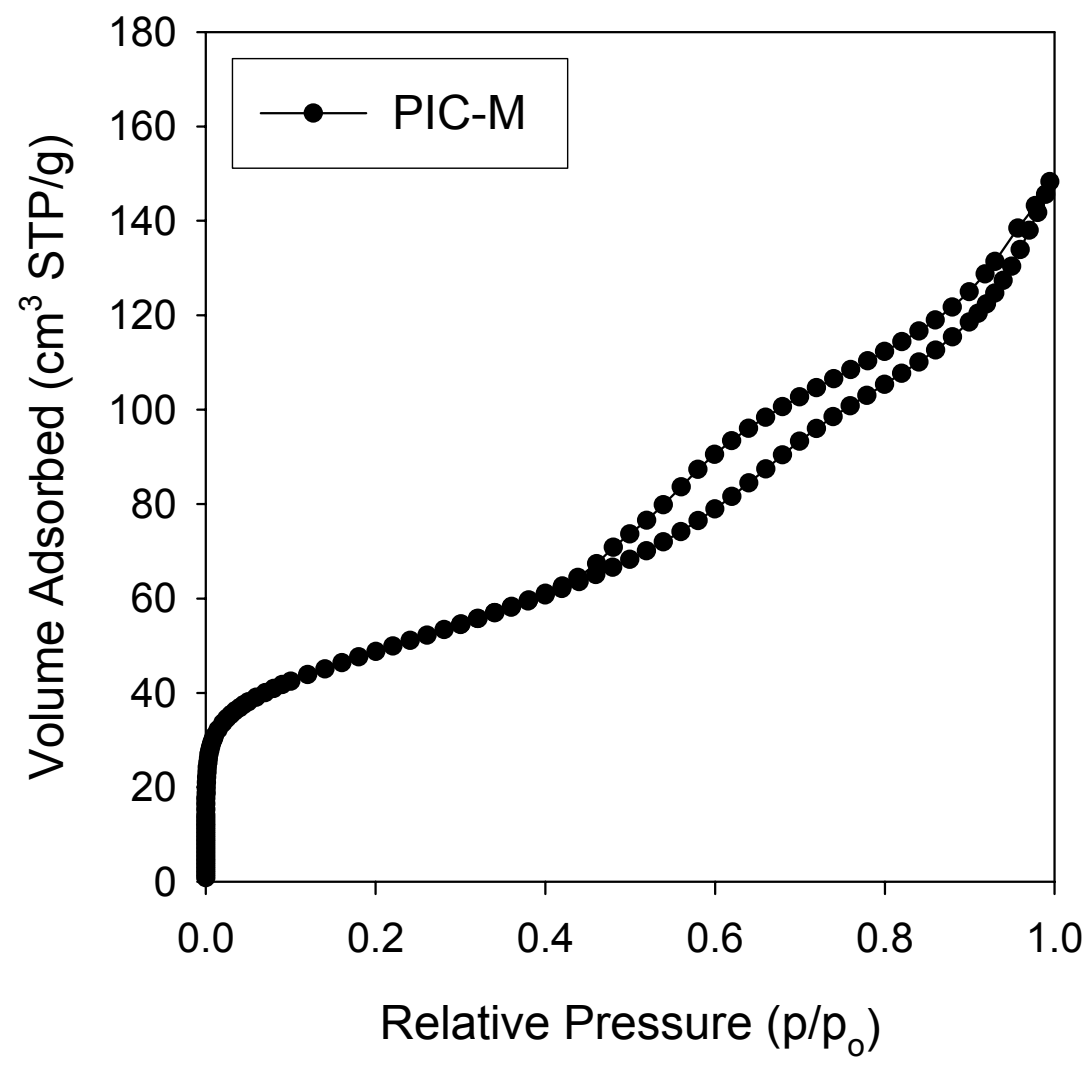

Figure 3S. Nitrogen adsorption isotherm for the PIC-M sample at $-196{ }^{\circ} \mathrm{C}$. 